\title{
LIBRO DE NAVIOS Y BORRASCAS: EXILIOS E OUTRAS MIUDEZAS
}

\author{
Cecilia Zokner \\ Universidade Federal do Paraná
}

RESUMO

Libro de navios y borrascas, publicado em 1983, é um dos muitos romances escritos nesta década que trata do exílio. Seu autor, Daniel Moyano, argentino levado a aban. donar seu país em 1976, constrói nesse relato, a história de uma travessia onde se inscreve uma profunda e comovida reflexāo sobre os possiveis destinos do homem latinoamericano. A partir dos principais motivos da obra - a tortura, a prisão, o desaparecimento, o exilio - foram analisados os recursos que dela fizeram - como o queria Cortázar, não uma lamentação, mas uma vitória sobre o exilio, cristalizada em lirismo e testemunho. Para Isso servem as palavras.

No ano de 1988, Daniel Moyano foi convidado para a recepção oferecida pela Corte Espanhola, quando da entrega do Prêmio Miguel Cervantes ao mexicano Carlos Fuentes. Contou, depois, numa crônica publicada em El País ${ }^{1}$ que após o terceiro uísque - sentiu uma vontade muito grande de pedir ao Rei da Espanha, o anfitriāo, que fizesse algo pelos habitantes do Cone Sul. Afinal, como responsável consangüíneo do descobrimento da América, "poderia" contra qualquer dos ditadores que ainda ficam, especialmente Pinochet e Stroessner. Poderia mandar uma armada ou algo assim.

Independentemente de pedidos ou de armadas, os ditadores começaram a partir. Talvez outros cheguem e partam. Enquanto isso, a América ainda será por algum tempo o Continente das aves migradoras?

MOYaNo. Daniel. Un sudaca en la corte. El Pais. Madrid. 2 de mayo de 1988. p 1.6 zOKNER, Cecllia. Literctura do Coatinente: Mieraçes. o Estado do Parana. Curitlbs, 17 de setembro de 1989. p. 19. 
Migrações que obedecem a razões econômicas - são milhares os que abandonam seu próprio país em busca de meios mais dignos de vida - e do medo que têm os governantes latino-americanos dos intelectuais e dos artistas. Principalmente, quando não podem submetè-los por meio de privilégios ou impedir-lhes a critica do tradicional caos reinante na grande parte do Continente. Dai, sofrerem o mesmo tratamento, usado para neutralizar inimigos políticos ou pretensos inimigos: a marginalização. Um processo que tanto pode significar a perda de um emprego, como a prisão, a morte, o desaparecimento, o exilio.

De exilios, certamente, a América Latina tem sido sempre muito pródiga. Talvez, nunca, como nos últimos anos, com tal constância.

Em 1978, quando se realizou, na França, o Colóquio de Cerisy, "A literatura Latino-Americana de hoje";, o tema tratado por Julio CORTÁZAR foi "América Latina: Exilio e Literatura". Incisivo, ele esclarece que seu objetivo não será lamentar, mas responder "o mais ativamente e o mais eficazmente possivel ao genocidio cultural" que acontece diariamente em tantos países da América Latina. Consciente de roçar a utopia, ele acrescente: "acredito que entre vós, escritores exilados, existem condiçōes para superar o desgarramento, o desenraizamento que nos são impostos pela ditadura e para desenvolver, a nossa maneira, os golpes que nos infligem cada novo exilio". No seu entender, transformar o negativismo do exílio, das lamentações aos gritos de revolta - o que assegura a vitória do inimigo - numa nova visão da realidade, fundamentada em valores que o trabalho do escritor poderá tornar positivos. Inverter o programa do adversário a partir de uma auto-crítica severa, de um enriquecimento intelectual que leve cada vez mais à lucidez, à busca de caminhos conduzidos pelo humor.

Exilado em 1976, aos quarenta e seis anos, Daniel Moyano teve que recomeçar sua vida em Madrid. Na Argentina, onde nasceu, já havia publicado cinco livros de $\operatorname{contos}^{i} \mathrm{e}$ três romances ${ }^{i}$. Na Europa, apesar das dificuldades de adaptação à nova vida, continuou a escrever. Cinco anos depois,

3 Nesse Colóqulo, reajzado de 29 de junho a 9 de Jujho de 1978 no Centre Culture de Cerisy-Nasalle particlparam, entre outros, os tébicos Jacnues Leenhardit forea. nisador). Saul Yurkfevich. Noé Jitrik, Tzwetan Tadorov. Angele Rama, Rubén Ba. relro-Saguler e os ficcionistas Augusto Ron Bastos, Lezama Lima. Gerardo Mario Coloboff, Jose Donoso.

4 Publicado em COLloque DE CERISY, Littératuro latino-amerenine d'aujourd'hui, Paris: Unión Générale d'éditions, 1980. 444 p. p. 113-123.

5 COLLOQUE DE CERISY. p. 115.

6 Artista de variedades (1960). La lombriz (1964), El fucoo intorrumpido (1967), Mi música es para esa gente (1970). El estuche de cocodrilo (1970).

7 Una luz muy lejana 11966$)$. El oseuro (1968), El trino del diablo (1974). 
publicava pela Legasa El vuelo de tigre, romance escrito na Argentina e reescrito na Espanha. Nos últimos meses de 1981 e primeiros dias de 1982, escreve Libro de navios y borras. $\operatorname{cas}^{\mathrm{k}}$.

E bem possível que seja sua, a voz de Rolando, o narrador desse romance, quando diz que seu desejo primeiro fora contar as aventuras de um grupo de exilados em Madrid e em outras cidades da Europa. Num primeiro capítulo, breve, a saida do porto de Buenos Aires. A travessia, porém, foi invadindo os demais capitulos e as aventuras dos exilados na Europa ficaram sem contar.

Tenho que falar de um barco que zarpou do Cone Sul", diz Rolando. Em linhas anteriores, havia esclarecido que iria contar sua viagem, despretensiosamente, como quem não quer nada. Um pouco, também, para esquecer.

Num barco em que viajavam setecentos indesejáveis uruguaios, chilenos, argentinos - ele parte. Uma partida que se iniciara antes, no norte do país onde o foram buscar e o encontraram lustrando o violino embaixo da parreira. Sequer teve tempo de guardar o instrumento que lá ficou exposto às intempéries. No raio de sol que nele se pousou e no movimento que fez ao girar, o violino foi uma imagem luminosa, a última de sua terra que Rolando levou. Para a prisāo e para o navio que o levaria mais longe ainda. Quando ele zarpa, diante de Rolando e dos setecentos outros, Buenos Aires vai-se perdendo, vai-se desvanecendo.

Quatorze dias depois, numa cidade quieta, envolvida pela bruma do amanhecer, o barco encostou no cais. Os exilados começaram a desembarcar.

Entre a partida e a chegada, os dias foram de aprendizagem para Rolando e para as setecentas fotocópias da mesma história (p. 49). Primeiramente, das perdas que, num plano real significam ver-se privados daqueles objetos que sustentam o universo de cada um (a casa e a parreira que outras mãos irão podar, o violino desfazendo-se ao sol e à chuva), dos liames familiares (a tía que chegará para encontrar a casa abandonada, os velhos que ficaram sozinhos) ou referenciais (o Cruzeiro do Sul que não mais será visto no céu do Hemisfério Norte).

O cotidiano - as crianças em férias forçadas, pensar que um nenê recém-nascido pode ser o mascote do exílio, nomear um espetáculo de "teatro do exílio", pensar no chimarrão ou na eventualidade da volta, ensaiar as primeiras palavras

8 Publicado pela Legasa de Bucnos Aires em 1983.

$\mathfrak{a}$ Todas as citaçós referentes à Libro de navios y borrascas foram tiradas da cdicăo citada na nota anterior. 
em língua estrangeira - acaba levando ao "desmame", à assunção do exílio.

As interrogações sobre o porquê da expulsão do país, o sentir-se injustiçado nessa necessidade absurda de partir, levam o exilado a uma identidade nova, a de fazer parte de uma comunidade que, até então the fora desconhecida.

Uma nova identidade que se amplia na "verdade" dos outros. $O$ perceber que há nuanças entre os exilios. Alguns o sofrem pela primeira vez; outros, devem sofrê-los repetidas vezes; ainda, os que levam séculos de exílio no sangue como se consolam os judeus psicanalistas que também parte dos "setecentos" (p. 176). O perceber que pelas mensagens do poder que os expulsa, os exilados são os "tipos nojentos" que se foram mandados embora do país, por algo deve ter sido. Ou que, para o "ombudsman", o ouvidor defensor dos fracos, que os suecos inventaram há dois séculos, os expresos, exilados do Cone Sul ainda devem ser protegidos.

Se viajam tristes, cabisbaixos, bêbados, esses passageiros do Cristóforo Colombo pelo menos estão vivos, pelo menos nāo desapareceram (p. 55). Quantos arrancados intempestivamente, de casa, foram levados uma noite entre lanternas e latidos de cães e outras coisas (p. 297). Quantos interrogados. Humilhados (e o caminhar sem o cinto das calças e o locomover-se sem o cordão dos sapatos). Presos. Torturados. Mortos. Desaparecidos.

$\mathrm{E}$ no barco, nessas primeiras horas, nesses primeiros dias de liberdade, cada um reagindo a sua maneira. $O$ jovem buscando a buissola que lhe desse a certeza de que a viagem não era apenas um novo traslado para as prisões do Sul; Rolando, criando mundos de fantasia a partir de um pequeno pedaço de papel; alguém tocando a guitarra, alguém calando.

Motivos que, certamente, se prestam à lamentaçōes e à revoltas e que, no entanto, constroem uma narrativa em que os mais variados recursos - técnica da montagem dos episódios, polifonia narrativa, dosagem da informação, o "leitmotif", as digressões, a inserção do cômico - se enovelam para formar um corpus em que, embora sobressaiam o sentido lúdico do texto, jamais se afasta de sua intenção primeira: a denúncia das tragédias do Cone Sul.

Libro de navios y borrascas está construído em quinze capitulos, cujos títulos ou sintetizam o seu conteúdo' ou guardam com ele uma breve relação". Trata-se de uma narrativa linear da qual florescem episódios cuja dimensão varia.

10 Titlriteando, La Bahin, El Faro.

$11 \mathrm{Y}$ chau, Buenos Aircs; Petunias; Rasquidos: Naurraglos; El timonel; Vaca mirando el mar; Dlario de a bordo; Cadenza. El colibri, Como una llustón marina; ?Frn.. 
O episódio amoroso entre a baía e o navio se constitui um capítulo, assim como "a tragédia num ato" sobre a execução de Dorrego ou a história do faroleiro.

Episódios menores, muitos outros: a presença de Fernando Pessoa no cais de Lisboa, a mudança que marcou a infância de Paredes, o fantocheiro, a travessia das salinas, a história do húngaro e de Federico, a fantasia com Nieves. Como se fossem independentes do relato, a ele se prendem por liames, aparentemente muito tênues.

O episódio de Fernando Pessoa se inscreve uma vez na narrativa e com um objetivo muito claro: retardar o relato da chegada do Cristóforo Colombo a Barcelona. Dono absoluto de sua historia, o narrador afasta o tema que não the interessa "apagando-o para sintonizar a interferência". Inter. ferência que chegava ao barco, provinda de um homenzinho perto do cais do porto de Lisboa que olhava distraído a chegada dos navios (p. 282) e estabelecia com algum passageiro um diálogo telepático. Às perguntas que lhe foram feitas, Fernando Pessoa, pois é dele que se trata, respondia com versos do "Guardador de rebanhos". Assim como o haviam vislumbrado - olhos fechados por trás dos óculos e chapéu inclinado para a frente (p. 283) - e confundido com um mendigo, um bêbado, um tresnoitado, os passageiros o perderam de vista e a interferência cessou.

Os outros episódios surgem a partir de uma situação, de um objeto, de uma referência.

A mudança de hemisfério, levará Paredes, o fantocheiro, a reviver a mudança de casa. Primeiro incompreensivel para seus poucos anos e depois inaceitável pelo abandono do cāo deixado preso na casa vazia para impedir que seguisse o caminhão da mudança; também levarà à narração da tra. vessia das salinas, numa noite estrelada.

Dois episódios se relacionam com a confecção de instrumentos musicais: o que relata o aparecimento Gryga, o violino de Rolando, e aquele que narra a confecção da guitarra de Federico.

Gryga apareceu no povoado trazido pelo húngaro que chegou faminto. O tempo passou um pouco, um pouco o húngaro aprendeu a falar. Vivia num rancho com a boba do povoado. Seus dois amores, a mulher e o instrumento. A ambos abandonou numa noite em que partiu para atravessar as cordilheiras e encontrar o outro lado do mar.

Já a guitarra de Federico foi por ele confeccionada da árvore que esperou crescer e cuja madeira preparou, molhando nas chuvas e torrentes, na neve da cordilheira, deixando-a repousar ao sol. Federico nada mais fez na vida além da guitarra e quando ela ficou pronta, ele morreu. 
Para ajudar Rolando nos seus primeiros passos do exílio, o cozinheiro do barco, um espanhol que há quarenta anos navegava - pois no seu país só podia entrar à luz da lua e pela janela - lhe dá um papelzinho. Nele, escrito o endereço de sua sobrinha Nieves. A partir desse pequeno papel, Rolando construirá situações em que a figura feminina irá se desenhando, delicadamente erótica.

Esses vários episódios nem sempre será Rolando, o narrador protagonista, que os enunciará. Outras vozes - a do autor, a de outro personagem ou a de um narrador onisciente se farão cargo do relato.

Quando aparece no relato o episódio de Nieves é Rolando que o enuncia, relacionando-o sempre ao papelzinho que o originou. Assim, a partir do momento em que possui o endereço de Nieves, ela passa a ser real. Ao contrário daquelas fantasias elaboradas na prisão que existiam somente para ir aguientando pois a imagem feminina se diluia a cada noite com o sono e no dia seguinte era como se jamais tivesse existido (p. 58).

Rolando imagina aproximando-se da casa de Nieves, em Madrid, entrevendo seu braço branco e seus ombros nus através da cortina clara da janela, onde florescem os vasos de petúnias. Quando se trata, porém, de contar o encontro com Nieves, ele prefere ceder sua voz a outro e escolhe a voz de Bidoglio. Na busca de verossimilhança, Bidoglio altera a história, inclusive nos detalhes: muda o endereço de Nieves, sua profissão, o traje com que Rolando se apresenta no encontro e o trajeto que fizeram os dois passeando por Madrid.

Uma ou outra vez, também acontece que é a própria voz do autor que irá emergir do relato.

O episódio da travessia das salinas se insere no relato no momento em que mudam os hemisférios. A partir de uma associação - pensando que atravessar o mar para ver estrelas diferentes era como atravessar as salinas para ver algo verde e tomar um pouco de ar fresco (p. 172) - seu objetivo $^{12}$, segundo o narrador-protagonista, será eludir o tema da tortura de Sandra. Quem narra a travessia das salinas, no entanto, é o autor. Também em outro pequeno texto ele está presente em meio à fala de Rolando, sintetizando algumas de suas dúvidas como autor ${ }^{13}$ : teria preferido continuar a tocar em surdina, poetizar a coisa noutro capítulo, como o da baía, ampliar as visões de Contardi sobre o Guarda-Sol e me

\footnotetext{
12 Ese abjetivo de eludir um assunto dificll de ser narrado será cxplicado mais adiante, a página 184 .

13 Permita-se intuir que o eplsódio das salinas seja narrado pelo Autor embora as referéncias a ele relacionadas (as páginas 102 ou 173, por exemplo) foram leitas pelo narrador-protagonista.
} 
esquecer de seu filho desaparecido ou inventar um amor meio porno, meio erótico entre Sandra e o Gordinho e muito sexo para vender cem mil exemplares desta espécie de romance do qual ainda nāo sei como será o título (p. 193).

Na qualidade daquele que tudo sabe e tudo pode saber, um narrador onisciente irá contar o episódio da baía, o espetáculo de fantoches e o episódio da infância do fantocheiro. Apossando-se da voz do narrador-protagonista oferecerá as informações que a ele são sempre negadas. Não apenas irá contar as emoções do relacionamento amoroso vividas pela baía e pelo Cristóforo Colombo como também o que se passava no coração do fantocheiro quando era menino. Inclusive, irá colocar no mesmo nivel ficcional os personagens do romance e os personagens do teatro de fantoches durante o espetáculo do "teatro do exílio".

No entanto, se o narrador de Libro de navios y borrascas é polifônico, caberá sempre ao narrador-protagonista o dominio do relato. Somente ele é quem irá decidir o quê e como contar.

Rolando se confessa como que obrigado a narrar a sua viagem. Ou para esquecer ou para deixar testemunho, ele o fará. Inicia pelo momento em que foi preso, na sua casa em La Rioja para, em seguida, contar as condiçōes de seu embarque no Cristóforo Colombo. A viagem para Buenos Aires e a experiência da prisão que antecederam, são omitidas. No decorrer da narrativa, ele vai explicar: aquilo que foi omitido não vou dizer de jeito nenhum ainda que por causa dessa omissão tudo se deforme (p. 103).

Omissāo que também irá ocorrer no que se refere à tor. tura sofrida por Sandra. Um silencio imposto pelo próprio personagem, quando seu braço mutilado foi visto pelos demais. Ao levantá-lo para se despedir de uma estrela, na passagem do hemisfério, a manga, presa ao punho, se soltou e caindo para o ombro deixou o braço exposto. Rapidamente, ele foi escondido, mas as palavras de surpresa de Bidoglio, pronunciadas com voz terrivel - Meu Deus, o que é isso, queimaduras ou o quê? (p. 184) - permaneceram no ar mais tempo do que a visão do braço martirizado. E, cada um que cstava ali no convés do barco para ver, quem sabe, pela últi. ma vez, o Cruzeiro do Sul, foi dominado por vis lembranças da própria experiência.

Sandra foi se calando e alguém lhe diz: evitando falar no assunto não vamos suprimir a realidade. Interpelação que a obriga a explicar-se: isso está acima de minhas possibilidades. O melhor é esquecer, pelo menos isso me dá a ilusão de que não existem e me permite continuar sendo Sandra (p. 186). 
Para Rolando, mais tarde, ela irá contar espontaneamente e, então, será ele quem se negará a falar sobre o que ouviu e sobre o que viu no seu corpo. Para tratar de torturas e carnificinas é preciso ter coragem, pensa Rolando. Outros que o façam, eu sou um narrador de água doce, ele diz, capacitado para transportar laranjas ou ameixas no delta do $\mathbf{P a}$. raná ou fazer viagens de cabotagem. Nada além disso. Não sei nada do mar e menos de navegar. Se falo do mar, o faço obrigado pelas circunstâncias (p. 196).

Incapacidade que irá nortear a sua narrativa. Ele sabe que deve deixar testemunho, para isso servem as palavras (p. 181). Sua indole, porém, o inclina para o romance pastoril, para o pampa imaginado, para o gado e para a messe, maravilhosos mundos sem desaparecidos nem assassinados (p. 207). Ou, mais incisivamente: e eu falando de uns amores secretos entre uma baía e um barquinho, querendo inventar para Sandra um amor como Deus manda quando já a haviam violado quase todos os carcereiros (p. 194).

Então, procura ganhar tempo, interrompendo a narrativa com lembranças da infância, breves relatos e episódios que buscam o risco.

Em dois momentos da narrativa, Rolando se dá uma trégua: um pequeno descanso, como para falar de outras coisas que nos distraiam e ajudem a superar tensōes (p. 33) e mais adiante: um descanso para esquecer as coisas escuras (p. 35). E, também deixa explícito que o episódio das salinas (o que foi contado pelo Autor) e o de Fernando Pessoa no cais de Lisboa, surgiram para eludir o que se passara com Sandra.

Em dois momentos do romance - relacionados com exílio, os mais tensos - o humor e o cômico conduzem à quebra de tensāo.

Quando os presos destinados ao exilio descem dos furgões e são conduzidos ao cais, finalmente, tem as mãos libertas das algemas, livres para segurar os documentos que recebem. Então, se ouve a voz: tanta comichão nas costas o tempo todo e agora que posso coçar, veja você, não coça mais (p. 18).

Logo depois, Rolando vai encontrar um soldado, antigo companheiro de escola. Como se fosse a exata materializaçăo do sentimento dos contrários de que fala Luigi PIRAN. DELLO ${ }^{1 .}:$ o rosto de homem mau que the tinha feito o tempo e o ofício não chegava a encobrir os olhos mansos (p. 22). E, em cada referência a ele, entremeada no relato do itinerário

14 Impressūo resultante di constataço de algo aue é contririo no que deverja se: PIRANDELI_O, Luiz. El humerismo. Buenos Alres: El Llbro, 1946. 
furgão/navio (onde viajavam presos/onde viajarão obrigados) e, claramente, exposta uma ambivalência que teria graça nāo fosse cristalizar-se o sorriso na compreensão de seu real significado que, sem dúvida, guarda o seu quê de trágico; com a mão que não segurava o fuzil deu umas palmadinhas amistosas nas costas de Rolando; a mão do fuzil tinha quarenta anos, a das palmadinhas, dez; a mão da infância deixou passar o pacote de erva que estenderam; despedaçam-se, rápido, dísse a mão do fuzil; mas a mão boa bez um rápido gesto de despedida.

Ainda neste trajeto para a liberdade, a presença de um elemento cômico - o cômico leva ao riso e supõe ausência de emoção ${ }^{15}$ - que não deixa de se identificar com o humor na medida em que impede o descomprometimento emotivo. Rolando, ao tentar embarcar, vê-se impedido por um novo controle devido à falta de um "papelzinho" que o declarava apto para viajar. No desejo de salvá-lo, quem o antecedia na fila de embarque, já na escada do navio, portanto já em jurisdição italiana, puxa-o por um braço enquanto o soldado, tentando detê-lo, puxa-o pelo outro. Ao mesmo tempo, os contendores discutem. Rolando, recém saido da cadeia, ainda não tem cinto e suas calças estão amarradas com barbante. Entre a ânsia de liberdade e o medo de retornar à prisão, Rolando é dominado por um medo maior: suportar que dissessem, Rolando, homem, esse que subiu no barco com as vergonhas balançando. Humilhante. Porque as cuecas que eu tinha eram um desastre, recebidas na cadeia. Dessas antigas com botões, mas sem botões. Eu balançava entre medos, desde estar na lista negra até cair na água, mas o mais terrivel era que rebentasse a tirinha de fio de sisal, perto do nó, como sempre (p. 31).

Trata-se de uma situação que, sem dúvida, provoca o riso. Não, sem que lhe suceda o doloroso constatar que algo mais permanece além desse riso, o absurdo da situação em que se vê envolvido um ser humano privado de seus direitos mais elementares como dispor de um traje correto ou, simplesmente viver na sua pátria. Instala-se, então, o sentimento dos contrários que, em relaçāo à América Latina, se justifica, sobretudo, ao significar "um caminho, uma informação, uma defesa de tese", como o entende ZIRALDO'".

Assim, no desembarque em Barcelona, é o próprio Ro. lando quem irá contar duas histórias cômicas sobre as difi. culdades encontradas por argentinos ricos ao chegar na Eu-

15 Ver SAINZ ROBLES. Federico Cartos. Ensayo de un diccionario de la Literatura. Madrid: Aruilat. 1972. 218 p. p. Gl3.

10 PINTO. Ziraldo Alves. Ningucin cniende de humor. Revista de Cultura Vozes, Pe. trópolis, abril de 1970. Y. 64, n. 3. p. 21-27. 
ropa em outros tempos. Uma forma de atenuar a tensāo provocada pelo desembarque o pintor Contardi, homem de setenta anos que, privado do uso de suas pernas teria que enfrentar o desembarque e o exílio.

Se dramas e tragédias se disfarçam, se escondem em risos e sorrisos, outras se diluem na fragmentação. Lembranças se insinuam no relato que se propóe Rolando, aos poucos, incompletas e acabam compondo um outro relato, um novo episódio. Assim, o episódio do Flaco.

Aparece logo no início na narrativa como para explicar algo sem importância: como o narrador-protagonista conseguiu a pequena mala onde carrega suas roupas. Quem me deixou esta mala estava um trapo quando foi embora. E se ele próprio era um trapo, que quer dizer de sua mala. Quando transladaram o Flaco, a roupa lhe dançava no corpo. Soavam. the os ossos sob os trapos quando foi embora e levantou a mão sem olhar para trás, mão dirigida a qualquer cela, puros ossos que se meneavam a caminho do traslado (p. 19).

Mais adiante, se tratará dos cordōes de seus sapatos encontrados na mala. Eram negros, mas assim mesmo serviram para amarrar os sapatos marrons de Rolando (p. 29,39). Ou do barulho de chaves abrindo a cela; ou das fantasias do Flaco, acreditando poder fabricar, com pedaços de camisas e pauzinhos de fósforos, asas que lhe permitissem sair voando da cadeia (p. 20); ou da exclamação do advogado: coitado, nem estava metido em nada sério ( $p .36$ ), $E$, finalmente: até que o transladaram, sem fósforos, claro, e do Flaco ninguém nunca mais soube ( $p .199$ ).

$\mathrm{E}$, notas insistentes, os "leit-motifs" que nāo deixam esquecer o número dos desgarrados - somos setecentos indesejáveis, setecentos idiotas, setecentos imbecis, setecentos fantocheiros, setecentos judeus do pampa sem o pampa, setecentos inocentes, setecentos caixöes de defunto que, em certo momento hiperbolicamente se transformam em setecentos milhões. "Leit-motifs" que tampouco deixam esquecer as raizes que ficam. Para Rolando, elas significam a perda do violino que lá ficou pendurado na vinha, com o brilho do azeite de nozes, sem ninguém que dele cuidasse abandonado às chuvas de outono.

$E$, obsessões outras que aparecem e reaparecem nas suas digressōes sobre palavras que adquiriram, nos uiltimos anos, no Cone Sul significados muito precisos e muito dolorosos: "adeus", "inocência", "nunca", "voltar", "desaparecer".

Sobre "adeus" e "inocência" o narrador-protagonista discorre uma vez. No momento da partida, monologando, ele se interroga sobre a despedida: em circunstâncias normais talvez tenha algum sentido dizer adeus. Nós éramos outro tipo 
de adeus. Adeus definitivo? Adeus sem adeus? Mandavam a gente embora e então, como dizer adeus? (p. 33).

A partir da exclamação do Gordito, quando o barco deixava Buenos Aires, somos inocentes (p. 42). Rolando se lembra do interrogatório a que foi submetido. Em mais de duas páginas, tece considerações sobre a maneira de responder interrogatórios: para chegar a ser tāo irreal como o interlocutor é necessário achar o tom justo. Um tom que deixe claro, ao se cruzarem as primeiras palavras que a inocência é óbvia e que portanto o interrogatório não tem sentido (p. 146).

"Nunca", "voltar" e "desaparecer", porém, retornam muitas vezes, como se cada uma das vozes do romance não pudessem deixar de pronunciä-las.

"Nunca" traduzindo o medo do irreparável, da viagem sem retorno: palavra de bicho. Galinácea, cinzenta, acorujada (p. 39). E o barco se afastando da cidade. $E$ os olhos percebendo essa realidade que desaparecia. $\mathrm{E}$ o dar-se conta de que o exilio era para valer. Então, nunca mais? Nem mesmo com a cabeça branca, dentro de vinte anos? (p. 36).

O verbo "voltar" se entrelaça com dúvidas, esperanças, interrogaçōes. Mas é na contaminaçāo com o circunstancial que adquire um sentido pungente. A frase olha, eu quero voltar e apenas estamos saindo (p. 36) não significa, apenas, um desejo de retorno. Tratando-se de um exilado aquele que a enuncia, passa a significar absoluta impossibilidade de realizar esse desejo. $\mathrm{E}$, também, pungente, a minimizaçāo otimista do peso do tempo que irá transcorrer: se a gente sabe que vai voltar, um par de anos de cxilio passará ligeiro (p. 56).

Se as circunstâncias que rodeiam o exilio introduzem nuanças no sentido de certas palavras, igualmente privilegiam significados. "Desaparecer" passou a significar, num momento preciso do Cone Sul, principalmente, morrer; "desaparecido" passou a significar morto. Porém, para alguns, apoiando-se na acepção "ocultar-se", desaparecer ainda pode significar uma louca esperança. Ambigüidade extremamente dolorosa. Mas, é evidente que o desespero pode levar a outros conceitos. Em Libro de navios y borrascas são emitidos, sobretudo, pelo pintor Contardi (cujos setenta anos e cabelos brancos não foram impedimentos para levá-lo ao exilio) quando lhe informam que seu filho não está no barco mas desaparecido. Num certo momento da narrativa, Rolando define: Desaparecido, essa palavra. Ela sozinha, movendo-se como o mar, num código desconhecido... Tão vasta como o mar, mas oculta. Sozinha. Não existem relatos de nauf rágios 
desse mar paralelo. Dessa palavra ninguém se salva, uma vez caído nela, para contar a história ( $p .35$ ).

Talvez, nessa frase do narrador possa estar contida a gênese de Libro de navios y borrascas. A necessidade premente e irrecusável de dar voz a essas caladas pela prisão, pelo desaparecimento, pela morte.

Daniel Moyano, entre os gritos de revolta e as lágrimas, escolheu a luta preconizada por CORTAZAR ${ }^{1 \top}$.

$\mathrm{E}$, em Libro de navios y borrascas, as palavras ou se alçam muito fortes ou apenas murmuram. Revelam e insinuam aproximando-se do riso e das lágrimas, movendo-se do real para o lúdico no desejo de resgatar do silêncio, na ânsia de deixar testemunho dessas aves migradoras do Continente cujo destino é, despoticamente, regido pelas leis das aves de rapina.

\section{REFERENCIAS BIBLIOGRAFICAS}

COLLOQUE DE CERISY. Littérature latino-americaine d'aujourd'hui. Paris: Unión Générale d'éditions. 1980. 444p. p.113-123.

MOYANO, Daniel. Libro de navios y borrascas. Buenos Aires: Legasa, 1983. $316 \mathrm{p}$.

—. Un sudaca en la corte. El País. Madrid. 2 de mayo de 1988, p.16. PINTO, Ziraldo Alves. Ninguém entende de humor. Revista de Cultura Vozes, Petrópolis, v.69, n.3, p.21-37, abril, 1970.

PIRANDELLO, Luiz. El humorismo. Buenos Aires: El libro, 1946.

SAINZ ROBLES, Federico Carlos. Ensayo de un diccionario de la Literatura. Madrid, Aguilar,

ZOKNER, Cecilia. Literatura do Continente: Migrações. O Estado do Paraná. Curitiba, 17 de setembro de 1989, p.19.

17 “Nós sabemos bem: é pouco o que podem fazer os escritores contra a máquina do imperialismo e do terror fascista nos nossos paises; mas, também é evidente que nesses últimos anos a denúncia pela Literatura dessB máquina e desse terror tem produzido um impacto crescente nos leltores estrangeiros e constitui, consequentemente, uma ajuda moral e prática para os movimentos de resisténcia e de luta". b. 122. 